\title{
Genetic and biochemical characterization of Bacillus subtilis 168 mutants specifically blocked in the synthesis of the teichoic acid poly(3-O- $\beta$-D- glucopyranosyl- $N$-acetylgalactosamine 1-phosphate): gne $A$, a new locus, is associated with UDP- $N$-acetylglucosamine 4-epimerase activity
}

\author{
Ana-Isabel Estrela, ${ }^{1,2}$ Harold M. Pooley, ${ }^{1}$ Herminia de Lencastre ${ }^{2}$ and \\ DIMITRI KARAMATA ${ }^{1 *}$ \\ ${ }^{1}$ Institut de Génétique et de Biologie Microbiennes, Rue César-Roux 19, 1005 Lausanne, Switzerland \\ ${ }^{2}$ Centro de Tecnologia Quimica e Biologica, Rua de Quinta Grande 6, Apartado 127, 2780 Oeiras, Portugal
}

(Received 25 September 1990; revised 4 December 1990; accepted 11 December 1990)

\begin{abstract}
The resistance spectrum to bacteriophage $\phi 3 \mathrm{~T}$ of different Bacillus subtilis 168/W23 strains hybrid for wall teichoic acids suggested that poly(3-O- $\beta$-D-glucopyranosyl- $N$-acetylgalactosamine 1-phosphate), a so-called minor teichoic acid of strain 168, forms part of the receptor for this phage, and a serologically related group of phages. A representative sample of 25 mutants specifically resistant to $\phi 3 \mathrm{~T}$, obtained from a mutagenized culture by direct selection, were all found to have a greatly reduced galactosamine content. Relevant mutations in these strains were shown by PBS1 transduction and transformation to belong to two linkage groups; a minority, associated with an atypical colony morphology, were localized between $\operatorname{sac} A$ and $\operatorname{pur} A$, whereas the majority mapped between $\operatorname{ta} B$ and $\operatorname{tag} B 1$ (formerly $\operatorname{tag}-1$ ), a region containing all known genes involved in the synthesis of the major wall teichoic acid, poly(glycerol phosphate). The former mutations mapped in a new locus, gneA, characterized by a deficiency in UDP- $N$-acetylglucosamine 4-epimerase, while the latter ones, as well as the previously identified pha-3 (Estrela et al., 1986, Journal of General Microbiology 132, 411-415), map in a locus named $g g a$. They are likely to affect membrane-bound enzymes involved in the synthesis of the galactosaminecontaining teichoic acid. A possible biological role of this polymer is discussed.
\end{abstract}

\section{Introduction}

Cell walls of many Gram-positive bacteria contain relatively large amounts of anionic polymers (Baddiley, 1970; Archibald, 1974). In Bacillus subtilis 168, several such polymers have been identified (Burger \& Glaser, 1964; Shibaev et al., 1973); the phosphate-rich poly(glycerol phosphate) [poly(groP)], glucosylated poly(groP) and poly(3-O- $\beta$-D-glucopyranosyl- $N$-acetylgalactosamine 1-phosphate) [poly(Glc-GalNAc 1-P)], present under conditions of saturating phosphate, are replaced by teichuronic acid (Janczura et al., 1961; Ward, 1981)

Abbreviations: DMAB, p-dimethylaminobenzaldehyde; GalN, galactosamine; GalNAc, $N$-acetylgalactosamine; GlcNAc, $N$-acetylglucosamine; MMC, mitomycin C; MNNG, $N$-methyl- $N^{\prime}$-nitro- $N$ nitrosoguanidine; ND, nephelometric density; $\phi 3 \mathrm{~T}^{\mathrm{R}}, \phi 3 \mathrm{~T}$ resistant; $\phi 3 T^{\mathrm{s}}, \phi 3 \mathrm{~T}$ sensitive; poly(Glc-GalNAc 1-P), poly(3-O- $\beta$-D-glucopyranosyl- $N$-acetylgalactosamine 1-phosphate); poly(groP), poly(glycerol phosphate). under phosphate-limiting growth conditions. Genetic analysis of conditional lethal mutants deficient in poly(groP) synthesis (Boylan et al., 1972; Karamata et al., 1972; Pooley et al., 1987; Briehl et al., 1989; Mauël et al., 1989), and in particular the more recent nucleotide sequencing studies (Honeyman \& Stewart, 1989; Mauël et al., 1991) have led to the identification of six genes likely to be specifically involved in the synthesis of glucosylated poly(groP). Putative enzyme activities for the encoded products of two of these genes have been proposed (Young, 1967; Pooley et al., 1991). In comparison, genetic information on the galactosamine (GalN) containing polymer is limited. No mutants specifically blocked in its synthesis have been identified. Of two markers known to affect its synthesis, neither $g t a B$, the putative structural gene for UDP-glucose pyrophosphorylase (Pooley et al., 1987), nor gtaC, which affects the activity of phosphoglucomutase (Young, 1967), is exclusively involved in the synthesis of this polymer. Both 
mutations lead to a diminished pool of a precursor, UDPglucose.

Presence or absence of GalN in walls of different $B$. subtilis $168 / \mathrm{W} 23$ hybrids, obtained by exchange of the tagBl (formerly tag-1) marker (Karamata et al., 1987), and known to have undergone variable deletions of the neighbouring genes of the 168 chromosome (Young et al., 1989), led to the conclusion that all or part of the genetic determinants for a GalN-containing polymer were located between the gtaA and gtaB loci (Karamata et al., 1987). The localization to this region of the chromosome of a new locus, pha-3 (Estrela et al., 1986), associated with a specific resistance to $\phi 3 \mathrm{~T}$ and closely related group III phages (Dean et al., 1978), but distinct from previously identified markers, gta $A$, gtaB , gtaD, raised the possibility that the poly(Glc-GalNAc 1-P) may play a role in the adsorption of these phages. Mutations in $\mathrm{gtaC}$ and gtaB confer resistance to $\phi 3 \mathrm{~T}$ and serologically related phages, whereas gtaA mutations allow infection (Estrela et al., 1986). While mutations in all the gta markers prevent glucosylation of the major cell wall teichoic acid, poly(groP), those in $g t a B$ and $g t a C$ are associated, unlike gta $A$, with greatly reduced amounts of $N$-acetylgalactosamine (GalNAc) in cell walls (Young, 1967; Pooley et al., 1987).

As resistance to $\phi 3 \mathrm{~T}$ is correlated with the absence of the GalNAc-containing polymer, we verified the resistance spectrum to $\phi 3 \mathrm{~T}$ of a selection of $168 / \mathrm{W} 23$ strains hybrid for wall teichoic acids (Karamata et al., 1987) known to differ in their GalN content, and then proceeded to isolate a representative collection of $\phi 3 \mathrm{~T}^{\mathrm{R}}$ mutants blocked in the synthesis of the GalN-containing polymer. We report here the genetic analysis and biochemical characterization of these mutants.

\section{Methods}

Strains. The $B$. subtilis strains used are listed in Table 1 . Bacteriophages $\phi 25, \phi 29$ and SPOI were from laboratory stocks; $\phi 3 \mathrm{Tc}, \rho 1 \mathrm{lc}, \phi 105 \mathrm{c}$ and SPO2c were spontaneous clear plaque mutants. Stocks of the above phages and SPR were prepared on strain YB886 as previously described (Estrela et al., 1986).

Media. M broth, M agar and M soft-agar (Yehle \& Doi, 1967) supplemented as described by Yasbin et al. (1973) were used to assay phage adsorption and infection. L medium, TS plates and SAT medium as well as media for transformation and transduction were as previously described (Karamata \& Gross, 1970; Pooley \& Karamata, 1984; Karamata et al., 1987). Minimal medium was supplemented with amino acids $\left(20 \mu \mathrm{g} \mathrm{ml}^{-1}\right)$ and bases $\left(100 \mu \mathrm{g} \mathrm{ml}^{-1}\right)$ when necessary. $\operatorname{sacA^{+}}$ and $\operatorname{ctr} A^{+}$transductants were selected on a modified Spizizen's medium (Dedonder et al., 1977) containing $0.1 \%$ sucrose $\left(\operatorname{sac~} A^{+}\right)$in place of glucose or $0.1 \%$ glutamate in place of ammonium $\left(c t r A^{+}\right)$.

Biochemicals. UDP- $N$-acetylgalactosamine and mitomycin C (MMC) were purchased from Sigma, $\mathrm{N}$-acetyl $\left[1-{ }^{14} \mathrm{C}\right]$ glucosamine from Amersham, and $p$-dimethylaminobenzaldehyde (DMAB) from Merck.
Phage assay. Phage infection and determination of efficiency of infection were as described by Estrela et al. (1986). Suitable dilutions of phage lysates were allowed to adsorb to $10^{8}$ cells for $15 \mathrm{~min}$, at room temperature, before plating in top agar.

Mutagenesis and selection of phage-resistant mutants. Strain SL1020 was grown on SAT medium and cells were mutagenized with $N$-methyl$N^{\prime}$-nitro- $N$-nitrosoguanidine (MNNG) as described by Karamata \& Gross (1970). After addition of the mutagen, the culture was divided into five tubes, and incubated for $30 \mathrm{~min}$ at $37^{\circ} \mathrm{C}$. Survival, measured as viable counts, was $17 \%$ and frequency of auxotrophs was $10 \%$. The mutagenized cultures were diluted 20 -fold into $\mathrm{L}$ medium, and further incubated overnight at room temperature to allow expression. $\phi 3 \mathrm{~T}$ was added to appropriate dilutions of the five sub-cultures, at a multiplicity of infection of 10-100. After $15 \mathrm{~min}$ at room temperature, to allow adsorption, $0.1 \mathrm{ml}$ samples were plated in top agar overlays and incubated overnight at $30^{\circ} \mathrm{C}$. Plates with well-distributed surviving colonies (representing from 1 to $4.8 \%$ of the inoculum from different sub-cultures) were chosen and, from certain plates, all colonies were picked and streaked. The spectrum of resistance to phages $\phi 3 \mathrm{~T}, \phi 25$, $\phi 29$ and $\phi 105$ of about 90 colonies was examined as previously described (Estrela et al., 1986). Approximately $7 \%$ of all isolates were found to be lysogenic for $\phi 3 \mathrm{~T}$ (see below). The overall frequency of mutants specifically resistant to $\phi 3 \mathrm{~T}$ in different sub-cultures varied from $8 \times 10^{-4}$ to $2 \times 10^{-3}$. These values are more than 100 -fold higher than the frequency, $5 \times 10^{-6}$, of spontaneous $\phi 3$ T-resistant mutants.

Lysogenic assay. $\phi 3 \mathrm{~T}$-resistant $\left(\phi 3 \mathrm{~T}^{\mathrm{R}}\right)$ colonies were tested for $\phi 3 \mathrm{~T}$ lysogeny by assaying supernatants of overnight shaken cultures grown in $\mathrm{M}$ broth at $37^{\circ} \mathrm{C}$ for spontaneously liberated phage. $\phi 3 \mathrm{~T}^{\mathrm{R}}$ resistant colonies which did not liberate phage were further tested for lysogeny by $\mathrm{MMC}$ induction. Overnight cultures in $\mathrm{M}$ broth were diluted to a nephelometric density (ND) of 5 in fresh prewarmed $M$ broth and incubated at $37^{\circ} \mathrm{C}$ with shaking until they reached a ND of 40 . MMC was added to a final concentration of $1 \mu \mathrm{g} \mathrm{ml}^{-1}$, and incubation continued for another $15 \mathrm{~min}$. Cultures were centrifuged and cells, resuspended in fresh pre-warmed $\mathbf{M}$ broth, were incubated at $37^{\circ} \mathrm{C}$ with shaking for at least $3 \mathrm{~h}$ or until lysis was visible. Supernatants were assayed for the presence of phage.

Genetic exchange. Methods for transformation and PBS1-mediated transduction have been previously described (Karamata \& Gross, 1970; Pooley \& Karamata, 1984).

Estimation of cell wall GalN by selective extraction from whole cells labelled with $[1-1+C] G l c N A c$. The method was as described by Pooley et al. (1987). The labelling medium contained $\left[{ }^{14} \mathrm{C}\right] \mathrm{GlcN} A c$ at a final concentration of $0.025 \mu \mathrm{Ci} \mathrm{m} l^{-1}\left(0.92 \mathrm{kBq} \mathrm{ml}^{-1}\right)$.

Preparation of cell-free extracts. Cell-free extracts for the assay of UDP-GlcNAc 4-epimerase were prepared according to Glaser (1959). They were obtained from $500 \mathrm{ml}$ cultures grown at $37^{\circ} \mathrm{C}$ in $\mathrm{NY}$ broth (Glaser, 1959) with aeration to a ND of 120 . Cells were harvested by centrifugation, washed in $0.05 \mathrm{M}$-Tris, $0.01 \mathrm{M}-\mathrm{MgCl}_{2}, 0.001 \mathrm{M}$-EDTA $\mathrm{pH} 7.5$ at $4{ }^{\circ} \mathrm{C}$, resuspended in $3 \mathrm{ml}$ of the same buffer and maintained at $0{ }^{\circ} \mathrm{C}$. Bacteria were ruptured by sonication and cell debris removed by centrifugation. The supernatant was stored at $-70{ }^{\circ} \mathrm{C}$ before assay.

Total protein determinations. Total protein in cell-free extracts was measured by the Bio-Rad protein assay using the microassay procedure (Bradford, 1976) with bovine serum albumin as standard.

Assay for UDP-GlcNAc 4-epimerase (EC 5.1.3.7). The assay, performed as described by Glaser (1959), uses the conversion of GalNAc to GlcNAc, which is accompanied by a three-fold increased colour yield when the hexosamine content is measured by the MorgenElson colour reaction as modified by Oguchi \& Oguchi (1979). Enzyme reaction mixtures contained $10 \mathrm{~mm}$-glycine, $1 \mathrm{~mm}-\mathrm{MgCl}_{2}, 0.1 \mathrm{~mm}$ - 
Table 1. Bacillus subtilis strains

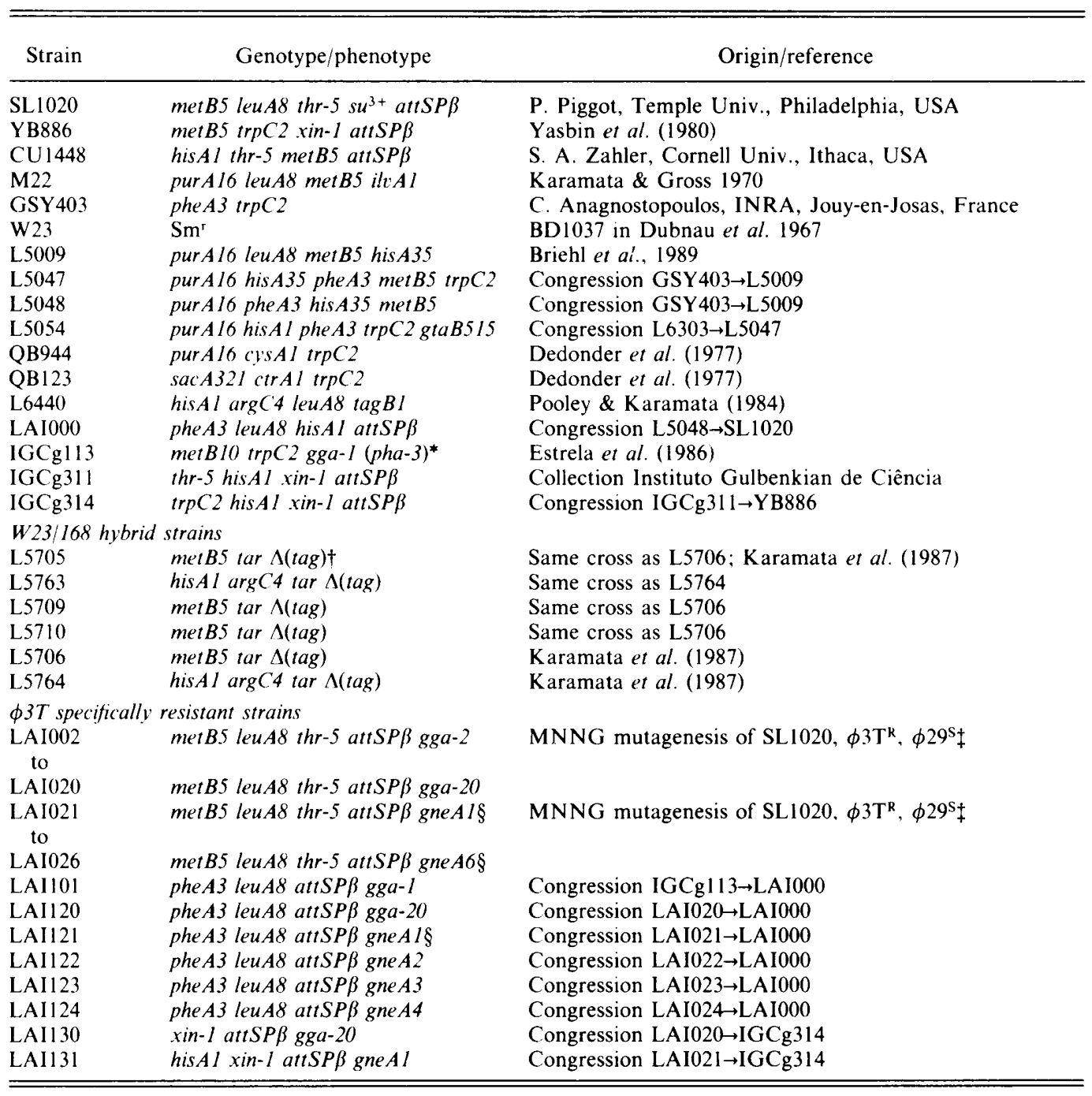

* Estrela et al. (1986); mutation pha-3 was renamed gga-I.

$\dagger$ tar represents the genetic determinants (Boylan et al., 1972) for the synthesis of the poly(ribitol phosphate) present in the cell wall.

$\ddagger \mathrm{R}$ and $\mathrm{S}$, resistant and sensitive, respectively to bacteriophages. See Results.

$\S$ Mutations in the gneA locus are associated with an atypical colony morphology (see text).

EDTA, $0 \cdot 1 \mathrm{~mm}$-UDP-GalNAc and $200 \mu \mathrm{l}$ of suitable dilutions of the cell-free extract in a final volume of $0.5 \mathrm{ml}$ at $\mathrm{pH} 9$. After $10 \mathrm{~min}$, the reaction was stopped by addition of enough $\mathrm{HCl}$ to bring the $\mathrm{pH}$ to $2 \cdot 0$, and the reaction mixture was incubated for $20 \mathrm{~min}$ at $100^{\circ} \mathrm{C}$. Reaction mixtures were neutralized with $\mathrm{NaOH}$ and total hexosamine was measured. GlcNAc and GalNAc standards were run simultaneously. Freshly prepared $1.5 \%(\mathrm{v} / \mathrm{v})$ acetic anhydride in acetone $(0.05 \mathrm{ml})$ was added to the neutralized reaction mixture. After $5 \mathrm{~min}$ at room temperature, $0.15 \mathrm{ml}$ of a $0.7 \mathrm{M}$-potassium tetraborate solution was added. Tubes were covered with glass marbles and heated in boiling water for $3 \mathrm{~min}$. After cooling $\left(15-23^{\circ} \mathrm{C}\right), 0.3 \mathrm{ml}$ DMAB reagent, prepared as described by Reissig et al. (1955), was added without shaking, followed by addition of $2.7 \mathrm{ml}$ glacial acetic acid. Incubation at $37^{\circ} \mathrm{C}$ for $20 \mathrm{~min}$ was followed by a $5 \mathrm{~min}$ cooling period in a water bath $\left(15-23^{\circ} \mathrm{C}\right)$. Absorbance at $585 \mathrm{~nm}$ was measured without delay.

\section{Results}

Resistance to phages $\phi 3 T$ and $\rho 11$ of W23/168 strains hybrid for wall teichoic acids

We sought further evidence for the proposed role (see Introduction) of the GalN-containing teichoic acid in the adsorption of phage $\phi 3 \mathrm{~T}$, and related phages, by examining the adsorption and infection behaviour of these phages on W23/168 strains hybrid for cell wall teichoic acids (Karamata et al., 1987). These strains, the walls of which all contain poly(ribitol phosphate), instead of poly(groP), were divided into two classes with 
Table 2. Differential plating efficiencies of B. subtilis phages on 168/W23 strains hybrid for wall teichoic acids

Plating efficiencies are mean values of at least two different experiments, and are given as the ratio of the number of plaque-forming units (p.f.u.) obtained by plating on each strain to p.f.u. obtained by plating on the parental strain. Phages $\phi 29$ and SPO2c were used as controls; $\phi 29$ has an absolute requirement for glucosylated poly (groP) for adsorption, and SPO2c infection is unaffected by mutants devoid of this glucosylated teichoic acid. Cell walls of all 168/W23 hybrid strains, like W23, contain poly(ribitol phosphate) and lack poly(groP).

\begin{tabular}{|c|c|c|c|c|c|c|c|c|c|}
\hline \multirow[b]{3}{*}{ Phage } & & \multicolumn{2}{|c|}{ Parent strains } & \multicolumn{6}{|c|}{ Hybrids (168/W23) } \\
\hline & & \multirow{2}{*}{$\begin{array}{c}168 \\
M 22\end{array}$} & \multirow[b]{2}{*}{ W23 } & \multicolumn{2}{|c|}{ W23-like } & \multicolumn{2}{|c|}{ W23-like, $\phi 25^{\mathrm{R}}$} & \multicolumn{2}{|c|}{ Mixed-type } \\
\hline & & & & L5705 & L5763 & L5709 & $\mathrm{L} 5710$ & L5706 & L5764 \\
\hline & $\begin{array}{l}\text { GalNAc } \\
\text { content* }\end{array}$ & ++ & - & - & - & - & - & ++ & ++ \\
\hline$\phi 3 T \mathrm{c}$ & & 1 & $0+$ & 0 & 0 & 0 & 0 & $0 \cdot 25$ & 0.27 \\
\hline$\rho 1 \mathrm{lc}$ & & 1 & 0 & 0 & 0 & 0 & 0 & 0.61 & 0.52 \\
\hline$\phi 29$ & & 1 & 0 & 0 & 0 & 0 & 0 & 0 & 0 \\
\hline SPO2c & & 1 & 0 & 0 & ND & 0 & ND & 0 & ND \\
\hline
\end{tabular}

ND, Not done.

* Relative to the wild-type GalNAc content, ++ indicates a normal level and - , a near absence of GalNAc; for values, see Karamata et al. (1987).

$\dagger 0$ stands for $<10^{-8}$.

respect to their galactosamine content: 'W23-like', and 'mixed-type', devoid of and containing GalNAc, respectively. In agreement with the hypothesis made above (see Introduction), we found (Table 2) that only those hybrid strains which have a 168-like content of GalNAc were sensitive to $\phi 3 \mathrm{~T}$ and $\rho 11$, confirming previous observations with gta mutations (Estrela et al., 1986). Measurement of phage titres before and after adsorption to whole cells, performed as described by Estrela et al. (1986), revealed the failure of $\phi 3 \mathrm{~T}$ and serologically related phages to adsorb to wild-type cells from which the GalNAc-containing polymer had been selectively extracted (see Methods). This supports the involvement of this wall teichoic acid in the adsorption of these phages.

\section{Isolation and preliminary characterization of $B$. subtilis mutants resistant to phage $\phi 3 T$}

A collection of $89 \phi 3 \mathrm{~T}^{\mathrm{R}}$ mutants was isolated from a MNNG-mutagenized culture of strain SL1020, by direct selection. Those mutants which were shown not to be lysogenic for $\phi 3 T$ (see Methods) were further analysed for their resistance pattern towards phages whose adsorption is affected by gta mutations, in particular towards $\phi 29$, which has an absolute requirement for glucosylated poly(groP), and $\phi 25$, which is able to infect gtaA-carrying mutants but not those bearing gtaB or gtaC mutations (Young, 1967; Pooley et al., 1987).
Nineteen mutants resistant to $\phi 29$ and $\phi 25$ in addition to $\varnothing 3 \mathrm{~T}$ were considered to harbour $\mathrm{gtaB}, C$, or $E$ mutations and were not further studied. The remaining mutants, all specifically resistant to phages $\phi 3 \mathrm{~T}$ and $\rho 11$, were retained for further study. They were characterized by the presence of a glucosylated poly(groP), as revealed by sensitivity to $\phi 29$.

\section{Distribution of $\phi 3 T^{\mathrm{R}}$ mutants into linkage groups}

Genetic analysis was focused on 25 mutants specifically resistant to $\phi 3 \mathrm{~T}$. They included all 14 isolates from one mutagenized sub-culture as well as representatives with all types of colony morphology originating from different sub-cultures. The spontaneous $\phi 3 \mathrm{~T}^{\mathrm{R}}$ mutant (Estrela $e t$ $a l ., 1986)$ containing the pha-3 mutation localized in the his $A I$ region of the chromosome was also included in our analysis. Preliminary assignment of mutations to linkage groups was achieved by PBS1 transduction. In the initial series of strains transduced, while, as expected, several mutations were found to be linked to hisAl, two did not map in this region. Transducing phage stocks prepared on one of the latter, and use of the Dedonder kit of recipients (Dedonder et al., 1977) revealed the presence of a mutation cotransducible with the sacA locus (see below). This mutation was associated with an atypical colony morphology (small, raised, round and brillant colonies) apparently indistinguishable from that pro- 
Table 3. Mapping of mutations gneAl and gga-20 by two- and three-factor PBSI transduction crosses

\begin{tabular}{|c|c|c|c|c|c|}
\hline Donor & Recipient & $\begin{array}{c}\text { Selected } \\
\text { marker }\end{array}$ & $\begin{array}{l}\text { Recombinant } \\
\text { class }\end{array}$ & $\begin{array}{l}\text { No. of colonies } \\
\text { scored }\end{array}$ & Implied order \\
\hline \multirow[t]{8}{*}{ LAI131 gneAl } & \multirow[t]{8}{*}{ QB944 purA16, cysAl } & pur ${ }^{+}$ & $\mathrm{Cys}^{+} \phi 3 \mathrm{~T}^{\mathrm{R}}$ & 0 & \multirow{8}{*}{ gne $A 1$, pur $A$, cys $A$} \\
\hline & & & $\mathrm{Cys}^{+} \phi 3 \mathrm{~T}^{\mathrm{s}}$ & 24 & \\
\hline & & & $\mathrm{Cys}^{-} \phi 3 \mathrm{~T}^{\mathrm{R}}$ & 8 & \\
\hline & & & $\mathrm{Cys}^{-} \phi 3 \mathrm{~T}^{\mathrm{s}}$ & 42 & \\
\hline & & cys $s^{+}$ & Pur $^{+} \phi 3 \mathrm{~T}^{\mathrm{R}}$ & 0 & \\
\hline & & & $\mathrm{Pur}^{+} \phi 3 \mathrm{~T}^{\mathrm{S}}$ & 26 & \\
\hline & & & Pur $^{-} \phi 3 T^{R}$ & 0 & \\
\hline & & & Pur $^{-} \phi 3 T^{S}$ & 49 & \\
\hline \multirow[t]{8}{*}{ LAI131 gneAl } & \multirow[t]{8}{*}{$\mathrm{QB} 123 \operatorname{sac} A 321, \operatorname{ctr} A l$} & $s a c^{+}$ & $\mathrm{Ctr}^{+} \phi 3 \mathrm{~T}^{\mathrm{R}}$ & 13 & \multirow{8}{*}{$c t r A, \operatorname{sac} A$, gneAl } \\
\hline & & & $\mathrm{Ctr}^{+} \phi 3 \mathrm{~T}^{\mathrm{s}}$ & 36 & \\
\hline & & & $\mathrm{Ctr}^{-} \phi 3 \mathrm{~T}^{\mathrm{R}}$ & 32 & \\
\hline & & & $\mathrm{Ctr}^{-} \phi 3 \mathrm{~T}^{\mathrm{S}}$ & 19 & \\
\hline & & $c t r^{+}$ & $\mathrm{Sac}^{+} \phi 3 \mathrm{~T}^{\mathrm{R}}$ & 17 & \\
\hline & & & $\mathrm{Sac}^{+} \phi 3 \mathrm{~T}^{\mathrm{s}}$ & 33 & \\
\hline & & & $\mathrm{Sac}^{-} \phi 3 \mathrm{~T}^{\mathrm{R}}$ & 0 & \\
\hline & & & $\mathrm{Sac}^{-} \phi 3 \mathrm{~T}^{\mathrm{S}}$ & 50 & \\
\hline \multirow[t]{8}{*}{ LAI130 gga-20 } & \multirow[t]{8}{*}{$\mathrm{L} 6440$ his $A 1, \operatorname{tag} B 1$} & his $^{+}$ & $\mathrm{Tag}^{+} \phi 3 \mathrm{~T}^{\mathrm{R}}$ & 37 & \multirow{8}{*}{ his $A, g g a-20, \operatorname{tag} B l$} \\
\hline & & & $\mathrm{Tag}^{+} \phi 3 \mathrm{~T}^{\mathrm{S}}$ & 0 & \\
\hline & & & $\mathrm{Tag}^{-} \phi 3 \mathrm{~T}^{\mathrm{R}}$ & 7 & \\
\hline & & & $\mathrm{Tag}^{-} \phi 3 \mathrm{~T}^{\mathrm{S}}$ & 53 & \\
\hline & & $\operatorname{tag}^{+}$ & $\mathrm{His}^{+} \phi 3 \mathrm{~T}^{\mathrm{R}}$ & 43 & \\
\hline & & & $\mathrm{His}^{+} \phi 3 \mathrm{~T}^{\mathrm{s}}$ & 0 & \\
\hline & & & His $^{-} \phi 3 \mathrm{~T}^{\mathrm{R}}$ & 53 & \\
\hline & & & His $^{-} \phi 3 \mathrm{~T}^{\mathrm{s}}$ & 5 & \\
\hline
\end{tabular}

voked by gtaB and gtaC markers. Inspection of the selected $26 \phi 3 \mathrm{~T}^{\mathrm{R}}$ mutants revealed a total of six with this abnormal colony morphology. Two of the latter, strains LAI023 and LAI025, had a somewhat rougher, flatter, more irregular colony morphology, apparently intermediate between that of the remaining four and that of the wild-type. Mutations gne A2, $-3,-4$ and -6 were shown by PBS1 transduction to map in the same position on the chromosome as gneAl (see below). The transformational recombination index between the gneAl (LAI131) and gne $A 5$ mutations, associated with the most pronounced difference in colony morphology within this group, was 0.03 . The close linkage, consistent with their being alleles, identifies a new locus designated gne $A$ (for UDPGlcNAc 4-epimerase; see below).

Mutations in the remaining 20 mutants were mapped more precisely by transformation experiments using strain L5054 (trpC2, gtaB515) as recipient. Double $\operatorname{gta}^{+}$ $t r p^{+}$recombinants were identified among selected $t r p^{+}$ recombinants by loss of the characteristic colony morphology of the gtaB marker (see below). The correlation between $\mathrm{gta}^{+}$and loss of this colony morphology was always confirmed by a test for $\phi 29$ sensitivity. For each cross, between 20 and $24 \mathrm{gta}^{+}$ recombinants were scored for resistance to $\rho 11$, indicative of the presence of a gga marker (for glucose galactosamine phosphate; see below). For 20 donors, including the strain carrying the pha-3 marker, presence of a $g g a$ marker was inferred from the high proportion of $\rho 11$ resistance among $\mathrm{gta}^{+}$recombinants - a mean of $72 \%$ was found with extremes of $96 \%(g g a-8)$ and $42 \%$ (gga-14). The mean frequency of congression of an unlinked reference marker, pur $^{+}$, among $t r p^{+}$recombinants was less than $9 \%$ for all but one cross. Thus, genetic analysis reveals that mutations conferring specific $\phi 3 \mathrm{~T}$ resistance identified in the 26 mutants of our collection map in two regions of the chromosome.

\section{Mapping of mutations gneA1 and gga-20, representative of the two linkage groups}

Mapping, by two- and three-factor PBS1 transduction crosses, of mutations gne $I I$ and $g g a-20$, representative of the linkage groups localized in the sacA and gta $B$ regions, provided the order sacA, gneA, purA and his $A, \operatorname{gga} a \operatorname{tag} B$, respectively (Table 3 ). The results confirmed that mutations belonging to the gga linkage group lie in the same region as many other markers - gta A, gtaB, tagFl $(\operatorname{rod} C I), \operatorname{tag} B I(\operatorname{tag}-1)$ - directly or indirectly involved in cell wall teichoic acid synthesis. The probable location for $g g a$ markers between $g t a B$ and $\operatorname{tag} B$ (see above) was confirmed (unpublished results) by transformation of two representative markers gga-1 (pha-3) and gga-20 with clones from an EMBL3 $\lambda$ bank (Mauël et al., 1989). 
Table 4. Cell wall galactosamine content in representative $\phi 3 T^{\mathrm{R}}$ mutants

Cells labelled with $\left[{ }^{14} \mathrm{C}\right] \mathrm{GlcN} A \mathrm{c}$ were precipitated by $5 \%(\mathrm{w} / \mathrm{v})$ TCA and the GalNAc-containing polymer was selectively extracted by heating at $100^{\circ} \mathrm{C}$ for $30 \mathrm{~min}$ at $\mathrm{pH} 4$.

\begin{tabular}{lccc}
\hline \hline Linkage group & $\begin{array}{c}\text { Reference } \\
\text { mutation }\end{array}$ & $\begin{array}{c}\text { No. of mutants } \\
\text { examined }\end{array}$ & $\begin{array}{c}\text { Cell wall GalNAc* } \\
(\%)\end{array}$ \\
\hline gneA & $\begin{array}{l}\text { gneAI } \\
\text { gneA3 }\end{array}$ & 4 & $1 \cdot 0 \pm 0 \cdot 15$ \\
gga & gga-I & 20 & $4 \cdot 8 \pm 0$ \\
gne $\mathrm{A}^{+} \mathrm{gga}^{+}$ & & & $1 \cdot 7 \pm 0.5$ \\
parent strain & & & $18 \cdot 3 \pm 1 \cdot 5$ \\
\hline \hline
\end{tabular}

* Expressed as a percentage of total radioactivity incorporated in cell wall hexosamines. For each group indicated, values represent the mean of all mutants. They are based on at least two independent measurements for each mutant examined.

Table 5. UDP-GlcNAc 4-epimerase activity in cytoplasmic extracts of $\phi 3 T^{\mathrm{R}}$ mutants representative of different linkage groups

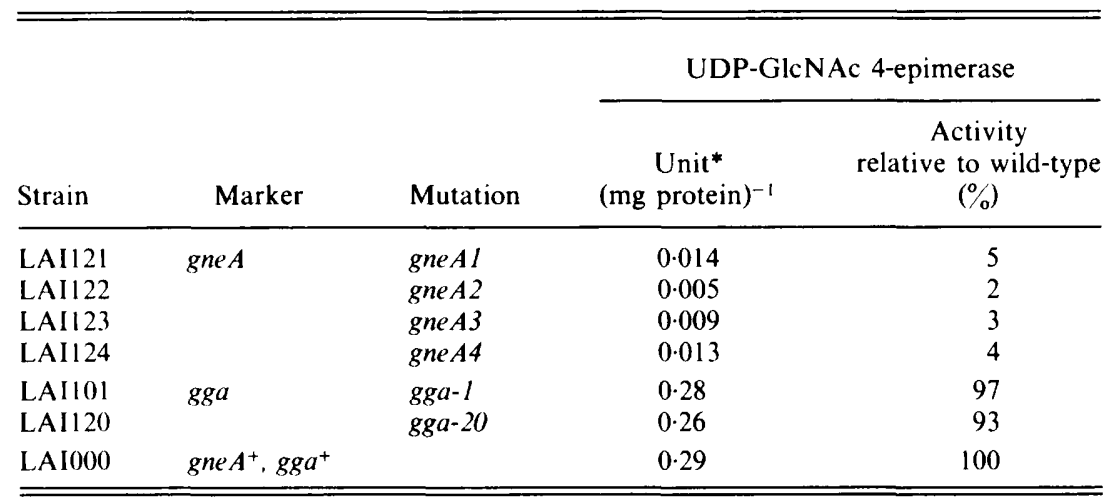

* One unit of enzyme is defined as the amount which catalyses the formation of $1 \mu \mathrm{mol}$ UDP-GICNAC under the conditions of the standard assay.

\section{Estimation of cell wall GalN content}

Genetically characterized mutants, bearing mutations in linkage groups $g g a$ and $g n e A$, were analysed for the GalNAc content of their walls. A selective extraction at $100{ }^{\circ} \mathrm{C}$ and $\mathrm{pH} 4$ of hexosamine-labelled cells was shown to specifically remove over $95 \%$ of the cell wall GalN (Pooley et al., 1987). The mutants had 4- to 18-fold less extractable cell wall GalN (hexosamine) label than the wild-type (Table 4). The average figure for $20 \mathrm{gga}$ mutations was $1 \cdot 7 \pm 0 \cdot 5$. That for the four gne $A$ markers associated with a characteristic colony morphology (see above) was $1 \cdot 0 \pm 0 \cdot 2$ while the two remaining gne $A$ markers, carried by strains LAI023 and LAI025, and associated with an intermediate colony morphology (see above), were identical, with amounts of $4.8 \%$. Results for the last-mentioned strains are consistent with a certain leakiness in the phenotype of mutations gne $A 3$ and gneA5. These results, obtained on a representative sample of randomly isolated $\phi 3 \mathrm{~T}^{\mathrm{R}}$ mutants, provide a clear confirmation that specific $\phi 3 \mathrm{~T}$ resistance is invariably associated with a marked reduction in the cell wall GalNAc content. Analyses of cell walls of several such mutants revealed phosphate and glycerol contents comparable to those of the parental strain SL1020 (data not presented), suggesting a normal level of poly(groP), in agreement with the $\phi 29$ sensitivity of these strains.

Assay of UDP-GlcNAc 4-epimerase activity in the soluble fraction of cell extracts

Since UDP-GalNAc is a specific precursor of poly(GlcGalNAc 1-P), a block in the formation of this precursor 
appeared to be a good candidate for a mutation that would lead to a specific inhibition of the synthesis of this polymer. UDP-GalNAc is formed from UDP-GlcNAc by the action of UDP-GlcNAc 4-epimerase, a cytoplasmic enzyme, whose presence in cell extracts of $B$. subtilis 168 was described by Glaser (1959). Assays of the activity in cell-free extracts of mutants belonging to the gga linkage group (Table 5) revealed a UDP-GlcNAc 4epimerase activity identical to that of the parent strain, whereas four mutants carrying a gne $A$ marker are all but devoid of epimerase activity, including one, LAI123, gneA3, containing significant cell wall GalN. This suggests that while the epimerase in the latter strain is inactive in the in vitro assay conditions, it has residual activity in vivo.

\section{Discussion}

Mutants specifically resistant to bacteriophage $\phi 3 T$ allow the definition of two linkage groups, gne $A$ and $g g a$, involved in the synthesis of poly(Glc-GalNAc 1-P), a so called minor wall teichoic acid, that can nevertheless account for $20 \%$ of the cell's hexosamine content. Genetic and biochemical analyses of these mutants have led to the identification of a new locus, gneA, linked to $\operatorname{sac} A$, which is likely to encode the UDP-GlcNAc 4epimerase catalysing the formation of UDP-GalNAc, a precursor of at least two anionic cell wall polymers, the poly(Glc-GalNAc 1-P) (Shibaev et al., 1973) and, during growth under phosphate limitation, the teichuronic acid (Ellwood \& Tempest, 1972). The high density of markers involved in teichoic acid synthesis at around $310^{\circ}$ of the B. subtilis chromosome is further underlined by the identification of one or several genes, designated gga, responsible for their $\phi 3 \mathrm{~T}^{\mathrm{R}}$ and cell wall GalN deficient phenotypes. Localization of $g g a$ markers between $\operatorname{tag} B$ and gtaB loci is in excellent agreement with genetic and cell wall analyses of different 168/W23 hybrid strains (Karamata et al., 1987), as well as with hybridization studies (Young et al., 1989). The gga loci are likely to encode membrane-linked enzymes involved in the synthesis of the poly(Glc-GalNAc 1-P). Indeed, identification of the gne $A$ locus, together with gtaB, the putative structural gene for UDP-glucose pyrophosphorylase, and gtaC, essential for phosphoglucomutase activity, means that all the enzymes necessary for the formation of known soluble precursors of the GalN-containing polymer, namely UDP-glucose and UDP-GalNAc, are now associated with loci other than gga. The preponderance of $g g a$ mutations, 19 out of a total of 25 , identified in a random sample of GalN deficient mutants, is consistent with a larger mutational target than that formed by the gneA locus.
Since this work was completed, insertional mutagenesis with clones of the gga region has revealed a single transcription unit of about $3 \mathrm{kbp}$ which, when disrupted, is associated with a $\phi 3 T^{\mathrm{R}}$ phenotype (Mauël et al., 1991). The coding capacity of this unit, equivalent to three average-size proteins of about $33 \mathrm{kDa}$, may be sufficient to accommodate several, if not all, membrane-bound enzymes required for the polymerization of poly(GlcGalNAc 1-P) (Hayes et al., 1977; Ward, 1981).

The virtual absence of GalN in the $20 \mathrm{gga}$ mutants examined here is consistent with the presence of a single GalN-containing cell wall teichoic acid, likely to be the poly(Glc-GalNAc 1-P), previously identified in this strain (Shibaev et al., 1973). The present study provides no support for the existence, in this strain and under the growth conditions used, of a second GalN-containing polymer (Duckworth et al., 1972).

Although the absence of poly(Glc-GalNAc 1-P) from walls of 26 mutants specifically resistant to Ø3T confirms previous results (Young, 1967) suggesting the dispensability of this polymer for cell growth, its biological role remains an interesting question. When a glycerol-requiring mutant is grown in the absence of glycerol, isolated cell walls contain, as expected, reduced amounts of the major teichoic acid, poly(groP), but increased quantities of GalN (Rosenberger, 1976). Certain tag (Ts) mutations, which are partially expressed at $30{ }^{\circ} \mathrm{C}$, are associated with a twofold or greater increase in wall GalN content relative to the tag $^{+}$allele $(\mathrm{H} . \mathrm{M}$. Pooley \& F.-X. Abellan, unpublished). These results can be interpreted in favour of a substitution role, i.e. within certain limits, the GalN polymer may be able to compensate a deficiency of poly(groP). If this explanation were correct, it would mean that this organism has at least two substitute polymers for poly(groP), one, poly(Glc-GalNAc 1-P), for phosphate-rich conditions and the other, teichuronic acid, for growth under phosphate depletion.

The maintenance of the genetic and enzymic capacity for synthesis of three distinct anionic polymers further underlines the importance of the role(s), so far unelucidated, of cell wall anionic or polysaccharidic polymers in the economy of this and, possibly, of other organisms.

The abnormal colony morphology associated with mutations in the gne $A$ locus, closely resembling that induced by mutations in the gtaB, gtaC and gta $E$ loci, was found to be a useful phenotype for genetic analysis. It is noteworthy that mutations in the above genes affect enzymes involved in the metabolic steps leading to soluble precursors of cell wall polymers whereas mutations affecting gga genes, likely to encode membranebound proteins, do not affect colony morphology. Thus, the altered morphology may be the result of a disturbance in the pools of soluble cell wall precursors provoked by a 
block in one of the enzymes leading to the synthesis of one or more of them.

Acknowledgements are made to FEBS for a fellowship to A.-I.E., and to Laurence Simon for competent technical help.

\section{References}

ARCHIBALD, A. R. (1974). The structure, biosynthesis and function of teichoic acids. Advances in Microbial Physiology 11, 53-95.

BADDILEY, J. (1970). Structure, biosynthesis and function of teichoic acids. Accounts of Chemical Research 3, 98-105.

Boylan, R. J., Mendelson, N. H., Brooks, D. \& Young, F. E. (1972). Regulation of the bacterial cell wall: analysis of a mutant of Bacillus subtilis defective in biosynthesis of teichoic acid. Journal of Bacteriology 110, 281-290.

BRADFORD, M. M. (1976). A rapid and sensitive method for the quantitation of microgram quantities of protein utilising the principle of protein-dye binding. Analytical Biochemistry 72, 248254.

Briehl, M., Pooley, H. M. \& Karamata, D. (1989). Mutants of Bacillus subtilis 168 thermosensitive for growth and wall teichoic acid synthesis. Journal of General Microbiology 135, 1325-1334.

BURGER, M. M. \& GlaSER, L. (1964). The synthesis of teichoic acids. I. Polyglycerolphosphate. Journal of Biological Chemistry 239, 31683177.

DEAN, D. N., ForT, C. L. \& Hoch, J. A. (1978). Characterization of temperate phages of Bacillus subtilis. Current Microbiology 1, 213-217.

Dedonder, R. A., Lepesant, J.-A., Lepesant-Kejzlarova, J., Billault, A., Steinmetz, M. \& Kunst, F. (1977). Construction of a kit of reference strains for rapid genetic mapping in Bacillus subtilis 168. Applied and Environmental Microbiology 33, 989-993.

Dubnau, D., Goldthwaite, C., Smith, I. \& Marmur, J. (1967). Genetic mapping in Bacillus subtilis. Journal of Molecular Biology 27 , 163-185.

Duckworth, M., Archibald, A. R. \& Baddiley, J. (1972). The location of $N$-acetylgalactosamine in the walls of Bacillus subtilis 168 . Biochemical Journal 130, 691-696.

ElLLWOOD, D. C. \& TEMPEST, D. W. (1972). Effects of environment on bacterial wall content and composition. Advances in Microbial Phy'siology 7, 83-117.

Estrela, A. I., DE LenCastre, H. \& ArCher, L. J. (1986). Resistance of a Bacillus subtilis mutant to a group of temperate bacteriophages. Journal of General Microbiology 132, 411-415.

GLASER, L. (1959). The biosynthesis of $N$-acetylgalactosamine. Journal of Biological Chemistry 234, 2801-2805.

HaYes, M. V., WARD, J. B. \& Rogers, H. J. (1977). The synthesis of an $\mathrm{N}$-acetylgalactosamine polymer by cell-free preparations of Bacillus subtilis. Proceedings for the Society for General Microbiology 4, 85-86.

Honeyman, A. L. \& Stewart, G. C. (1989). The nucleotide sequence of the rodC operon of Bacillus subtilis. Molecular Microbiology 3, $1257-1268$

Janczura, E., Perkins, H. R. \& Rogers, H J. (1961). Teichuronic acid: a mucopolysaccharide present in wall preparations from vegetative cells of Bacillus subtilis. Biochemical Journal 80, 82-93.
Karamata, D. \& Gross, J. D. (1970). Isolation and genetic analysis of temperature-sensitive mutants of Bacillus subtilis defective in DNA synthesis. Molecular and General Genetics 108, 277-287.

Karamata, D., McConnell, M. \& Rogers, H. J. (1972) Mapping of rod mutants of Bacillus subtilis. Journal of Bacteriology 111, 73-79.

Karamata, D., Pooley, H. M. \& Monod, M. (1987). Expression of heterologous genes for wall teichoic acid in Bacillus subtilis 168 . Molecular and General Genetics 207, 73-81.

Mauël, C., Young, M., Margot, Ph. \& Karamata, D. (1989). The essential nature of teichoic acids in Bacillus subtilis as revealed by insertional mutagenesis. Molecular and General Genetics 251, 388394.

Mauël, C., Young, M. \& Karamata, D. (1991). Genes concerned with synthesis of poly(glycerol phosphate), the essential teichoic acid in Bacillus subtilis strain 168, are organized in two divergent transcription units. Journal of General Microbiology 137, 929-941.

OGUCHI, M. \& OGUCHI, M. (1979). Tetraborate concentration on Morgen-Elson reaction and an improved method for hexosamine determination. Analytical Biochemistry 98, 433-437.

Pooley, H. M. \& Karamata, D. (1984). Genetic analysis of autolysindeficient and flagellaless mutants of B. subtilis. Journal of Bacterio$\log y$ 160, 1123-1129.

Pooley, H. M., Paschoud, D. \& Karamata, D. (1987). The gtaB marker in Bacillus subtilis 168 is associated with a deficiency in UDPglucose pyrophosphorylase. Journal of General Microbiology 133, 3481-3493.

Pooley, H. M., Abellan, F.-X. \& Karamata, D. (1991). A conditional-lethal mutant of Bacillus subtilis 168 with a thermosensitive glycerol-3-phosphate cytidylyltransferase, an enzyme specific for the synthesis of the major wall teichoic acid. Journal of General Microbiology 137, 921-928.

Reissig, J. L., Strominger, J. L. \& Leloir, L. F. (1955). A modified colorimetric method for the estimation of $\mathrm{N}$-acetylaminosugars. Journal of Biological Chemistry 217, 959-966.

Rosenberger, R. F. (1976). Control of teichoic and teichuronic acid biosynthesis in Bacillus subtilis 168trp-. Evidence for repression of enzyme synthesis and inhibition of enzyme activity. Biochimica et Biophysica Acta 428, 516-524.

Shibaev, V. N., Duckworth, M., Archibald, A. R. \& Baddiley, J. (1973). The structure of a polymer containing galactosamine from walls of Bacillus subtilis 168. Biochemical Journal 135, 383-384.

WARD, J. B. (1981). Teichoic and teichuronic acids: biosynthesis, assembly, and location. Microbiological Reviews 45, 211-243.

Yasbin, R. E., Wilson, G. A. \& YounG, F. E. (1973). Transformation and transfection in lysogenic strains of Bacillus subtilis 168. Journal of Bacteriology 113, 540-548.

Yasbin, R. E., Fields, P. I. \& Anderson, B. J. (1980). Properties of Bacillus subtilis 168 derivatives freed of their natural prophages. Gene 12, $155-159$

YeHLE, C. O. \& DoI, R. H. (1967). Differential expression of bacteriophage genomes in vegetative and sporulating cells of Bacillus subtilis. Journal of Virology 1, 935-947.

YouNG, F. E. (1967). Requirement of glucosylated teichoic acid for adsorption of phage in Bacillus subtilis 168. Proceedings of the National Academy of Sciences of the United States of America $\mathbf{5 8}$, 2377-2384.

Young, M., Mauël, C., Margot, Ph. \& Karamata, D. (1989). Pseudo-allelic relationship between non-homologous genes concerned with biosynthesis of polyglycerol phosphate and polyribitol phosphate teichoic acids in Bacillus subtilis strains 168 and W23. Molecular Microbiology 3, 1805-1812. 